\title{
Balloon Kyphoplasty for Osteoporosis: Technical Notes
}

\author{
Antoine Nachanakian, Antonios El Helou, \\ Sami Salem and Moussa Alaywan \\ Saint George Hospital University Medical Center, \\ Division of Neurosurgery, Balamand University \\ Lebanon
}

\section{Introduction}

Vertebral fractures are the most common fractures in osteoporosis and have significant impact on quality of life and survival rates, as well as carrying increased socioeconomic costs (Becker, S. 2008).

Kyphotic deformity results from those fractures are associated with increased morbidity and mortality (Johnell, O.1996; Edidin AA, et.al. 2011).

Balloon kyphoplasty is a minimally invasive procedure designed to restore vertebral body height, decreasing kyphosis, and also aims to achieve pain relief by stabilization of the fracture (Garfin SR. 2002)

In 1987, Galibert et.al described percutaneous vertebroplasty as an alternative of conventional treatment of vertebral fracture (Galibert $P$ et.al. 1987). The technique and the products used were developed until the description of balloon kyphoplasty in 1998 (Deramond, H . et. Al. 1998).

\section{Rational}

Balloon Kyphoplasty is performed nowadays by spine surgeons as well as by interventional radiologist. This is certainly an effective treatment of osteoporotic compression fracture, but it's more and more used in traumatic and metastatic fractures (Voggenreiter, G (2005); Wardlaw D. et. al (2009)).

Our experience is based on 176 cases of Balloon Kyphoplasty performed between 2004 and 2010. 136 cases were managed by transpedicular and 40 cases via extrapedicular approach. 82 cases were treated unilaterally and 94 cases were treated bilaterally. Decision for procedure was based on accessibility, extent of collapse and form of the pathological vertebra.

\begin{tabular}{|c|c|}
\hline Levels & No. of cases \\
\hline 1 & 146 \\
\hline 2 & 20 \\
\hline 3 & 6 \\
\hline 4 & 4 \\
\hline
\end{tabular}

Table 1. The number of vertebral levels treated in a single procedure 
Most patients were treated for vertebral fracture involving a single level (Table 1).

Fracture types are divided into four groups: Primary and secondary Osteoporosis, trauma and tumor (Table 2).

For secondary osteoporosis, chronic steroid use is the main etiology.

\begin{tabular}{|c|c|c|c|c|}
\hline Etiology & No. of cases & \% of cases & Cases & $\begin{array}{c}\text { Time of the treatment } \\
\text { Days }\end{array}$ \\
\hline Primary & 156 & 88.6 & 10 & $<10$ \\
Osteoporosis & & & 130 & $10-60$ \\
& & & 42 & $>0-90$ \\
& & & 4 & 2 \\
\hline Trauma & 10 & 5.7 & 4 & 31 \\
& & & 2 & 45 \\
& & & 2 & 50 \\
\hline Tumors & 6 & 3.4 & 2 & 3 \\
& & & 2 & 50 \\
& & & 2 & 65 \\
\hline Secondary & 4 & 2.3 & 2 & 48 \\
Osteoporosis & & & 2 & 72 \\
\hline Total Number & 176 & 100 & 176 & \\
\hline
\end{tabular}

Table 2. Etiology and number of patients with chronology of treatment

Vertebral fracture is confirmed through careful correlation of the patient's history, clinical examination, and radiological findings on X-ray's, CT scan and MRI.

The majority of vertebral osteoporotic compression fracture occurs at the thoracolumbar junction: 30 cases at Th12 level and 108 at L1 level (Table 3).

The duration between diagnosis of the fracture and the intervention was between 1 day and 90 days with a mean of 10 to 30 days (Table 4 ).

\begin{tabular}{|c|c|c|c|c|c|c|c|c|}
\hline Level & Th7 & Th8 & Th11 & Th12 & L1 & L2 & L3 & L4 \\
\hline No. of cases & 2 & 4 & 10 & 30 & 108 & 6 & 10 & 6 \\
\hline
\end{tabular}

Table 3. Number of compression fractures cases at each vertebral level

\begin{tabular}{|c|c|c|c|c|c|c|c|c|c|}
\hline $\begin{array}{c}\text { Duration before } \\
\text { treatment in Days }\end{array}$ & $1-3$ & $3-10$ & $10-20$ & $20-30$ & $30-40$ & $40-50$ & $50-60$ & $60-90$ & $>90$ \\
\hline No. of cases & 6 & 10 & 52 & 30 & 44 & 10 & 6 & 14 & 4 \\
\hline
\end{tabular}

Table 4. Period of symptoms prior to the treatment of vertebral compression fractures

\section{Decision making}

\subsection{Diagnostic criteria}

Patients are eligible for enrolment if they have:

- $\quad$ One to three vertebral fractures from Th5 through L5. 
- In case of multiple fractures, at least one fracture needs to have edema assessed by MRI and at least one has to show a 15\% loss of height or more in thoracic levels and $10 \%$ or more in Lumbar level

- In case of single fracture, it needs to meet both later criteria.

- The fractures treated are not chronic or occurred $>90$ days.

\subsection{Indication}

Indications for balloon kyphoplasty are (Lieberman IH, et. al (2001); Taylor RS, et.al (2007)) :

- Primary or secondary osteoporosis, multiple myeloma, or osteolytic metastatic tumors.

- Painful fractures with a back pain score of 4 points or more on a 0 - 10 scale. And, not responding to conservative treatment for 6 weeks.

- Adjacent vertebra of a fractured and treated one at the level of Th12 or L1 in severely osteoporotic patient, older than 75 years of age with good Karnofsky performance status score (>70). We found that, in 19 cases (7 L1 and 12 Th12 fracture), a fracture of Th12 vertebra occurred in case of previous balloon kyphoplasty on L1 at 18 months and vice versa.

\subsection{Contra indication}

Patients are excluded if they (Theodorou DJ, et. al (2002); Berlemann, U (2008)):

- $\quad$ Are younger than 21 years of age

- Have chronic fractures (estimated fracture age more than 3 months)

- Have pedicular fracture, previous vertebroplasty of the same vertebra, neurological deficit, radicular pain, spinal cord compression, or canal narrowing

- Are taking uninterruptible anticoagulation therapy

- Have allergies to kyphoplasty materials or contraindications to MRI

- Have dementia

- $\quad$ Are unable to walk before fracture (walking aids were allowed)

- Have vertebral fractures from primary bone tumours, osteoblastic metastases, or high energy trauma.

\subsection{Hospitalization and follow up}

In our institution, patients are admitted for 24 hours the same day of the procedure. In pre$\mathrm{op}$, the patient is asked to hold anti-platelets and other anti-coagulation for 5 days. Only LMWH can be tolerated up to 12 hours before the procedure.

Post op, spinal cord X-ray of the operated region is done. The patient is ambulated with abdominal belt for 1 month.

Usually, the patients had regular follow up at 1, 3 and 12 months.

\subsection{Biomechanics of cement injection}

Injection pressure and cement viscosity are the most important factors for injection. Studies show that the use of more viscous cement in association to lower injection pressure is advantageous for the regular spreading.

For this purpose, a geometrically modified cannulas and high viscosity cement were developed to decrease injection pressure and reduce the risk of insufficient filling of vertebral body (Berlemann,U (2008); Phillips, FM (2003); Vaccaro, A (2003)). 


\subsection{Surgery}

\subsubsection{Operative technique}

\subsubsection{Preparation}

The procedure is done under local-assisted anesthesia. The patient is in prone position on a radiolucent table in the operating room.

Double C-arm fluoroscopies are positioned. One is for AP view and the other is for lateral view. (Figure 1)

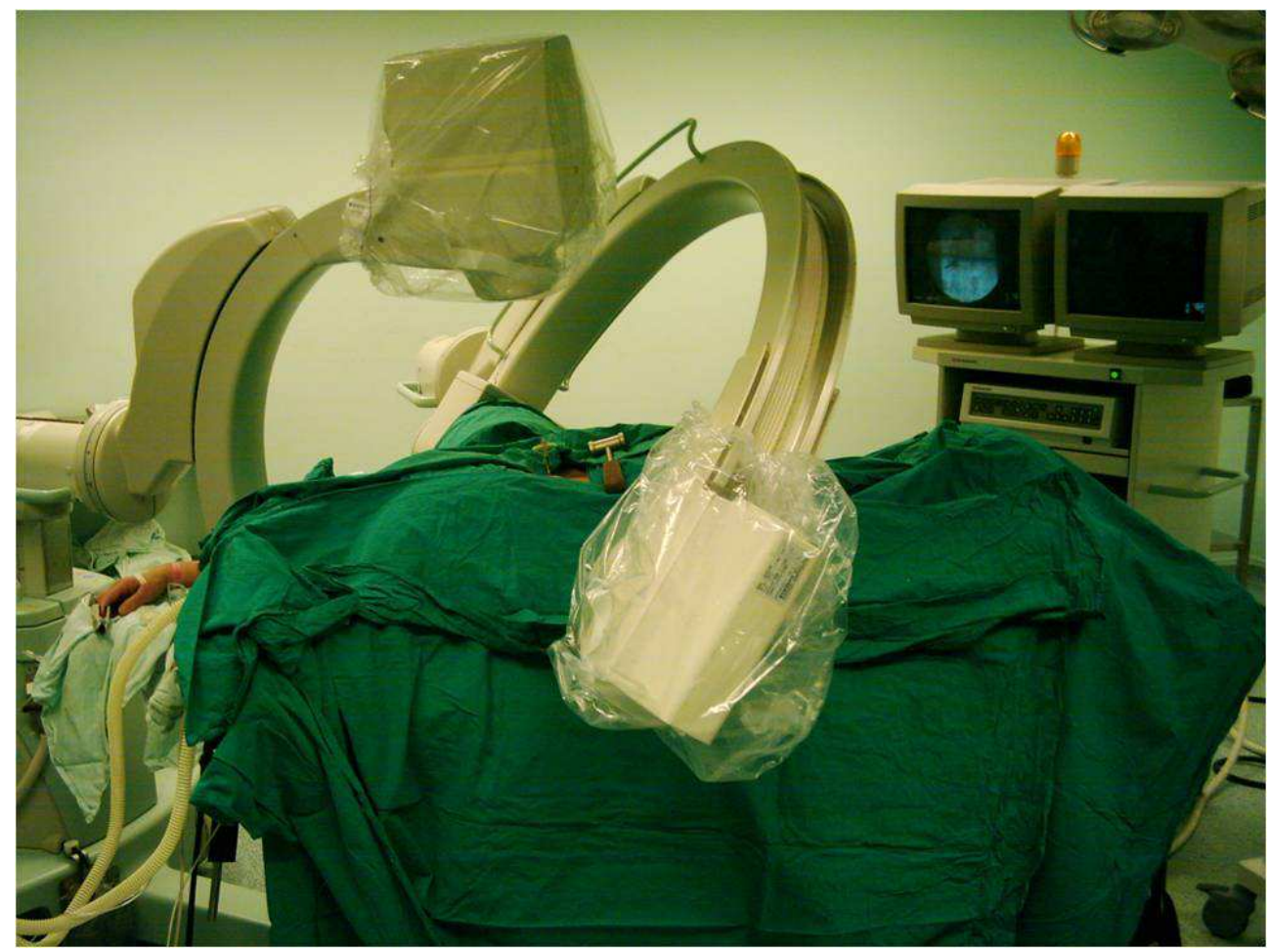

Fig. 1. Position of the patient with Antero-posterior and lateral C-arm.

\subsubsection{Product used}

Polymethylmethacrylate (PMMA) bone cement was the first used in balloon kyphoplasty. It consists of several ingredients that all have their importance. To site, PMMA is composed by methyl methacrylate, PMMA powder ,radio-opacifier, dibenzoyl peroxide, and other additives such as stabilizers, inhibitors, radical catchers, coloring agents and antibiotics (Berlemann,U (2008); Baroud G, Steffen T (2005); Bohner M, et.al (2003)).

PMMA is an easy handled product. It has an adequate balance between high viscosity, which reduces extravasation risks, and low viscosity, which enables low injection forces (Baroud G, et.al (2004); Weißkopf, M, et.al (2008)).

PMMA is allowed to cure for 3 to 5 minutes before injection to achieve a tooth paste viscosity. It needs 8 to 12 minutes in vivo to harden before removing injecting cannulas 


\subsubsection{The instrument used}

A basic instrument set with bone access tools is used in the procedure. The set contains the following (Figure 2):

- Scalpel

- Kocher clamp

- Jamshidi needle

- Hammer

- Kirschner wire

- Osteointroducer

- Kyphoplasty balloons with pressure seringue and manometer

- $\quad$ Bone filler

- Cement

- Dermal suture
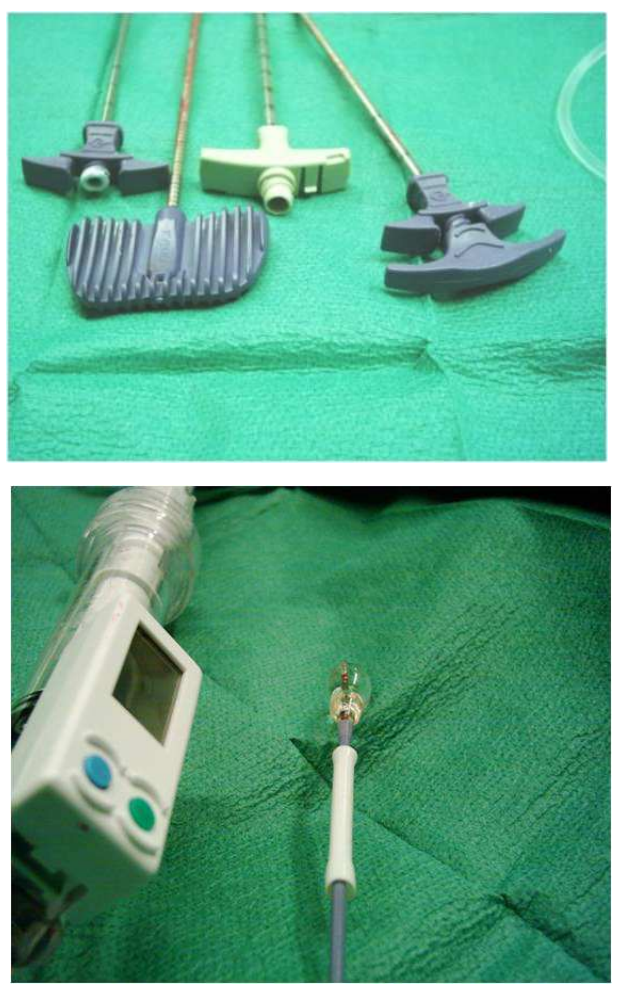

Fig. 2. Above: Jamshidi needle and 2 cement cannulas. Below: Kyphoplasty Balloon with pressure manometer

\subsubsection{Operative procedure}

The level of the pedicle of the fractured vertebrae is localized under fluoroscopy. A $3 \mathrm{~mm}$ incision is made at this level. An 11 gauge biopsy needle is advanced into the fractured vertebral body via Trans or extra-pedicular approach depending on the fracture configuration and patient's anatomy. 
A working cannula is inserted over the needle's trajectory. Once it's positioned, the needle is removed. (Figure 3)

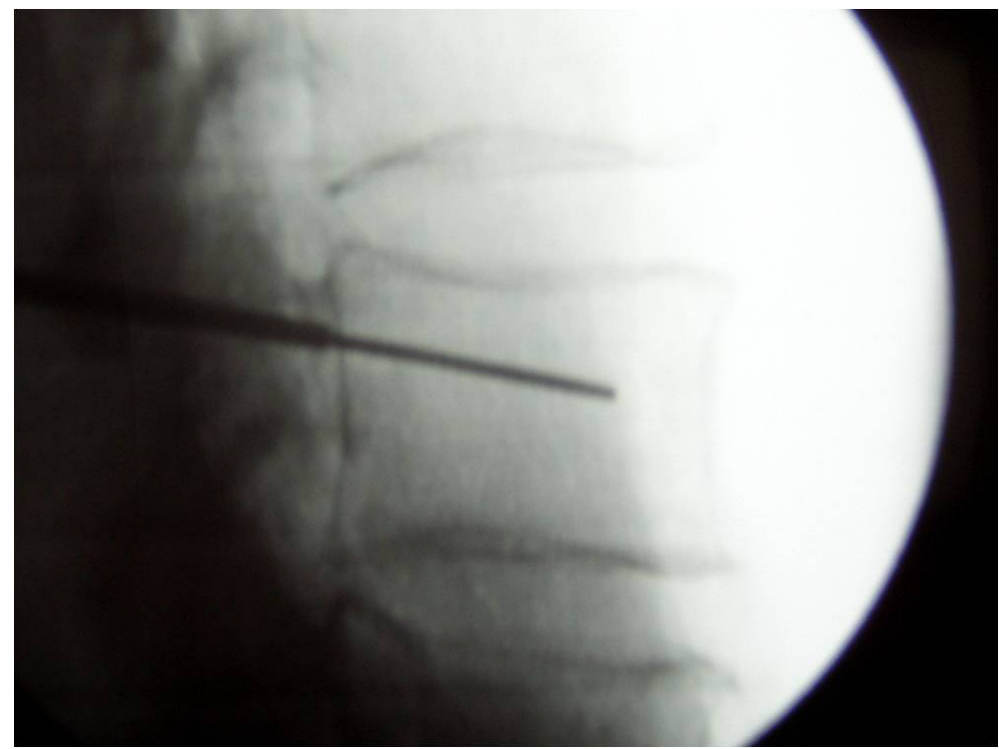

Fig. 3. Insertion of a working cannula.

An inflatable balloon tamp is advanced under the collapsed end plate.

Once inserted through the cannula into the vertebral body, the inflatable balloon tamps are expanded using fluoroscopic control. The volume and pressure are usually managed using the built in digital manometer.(Figure 4)
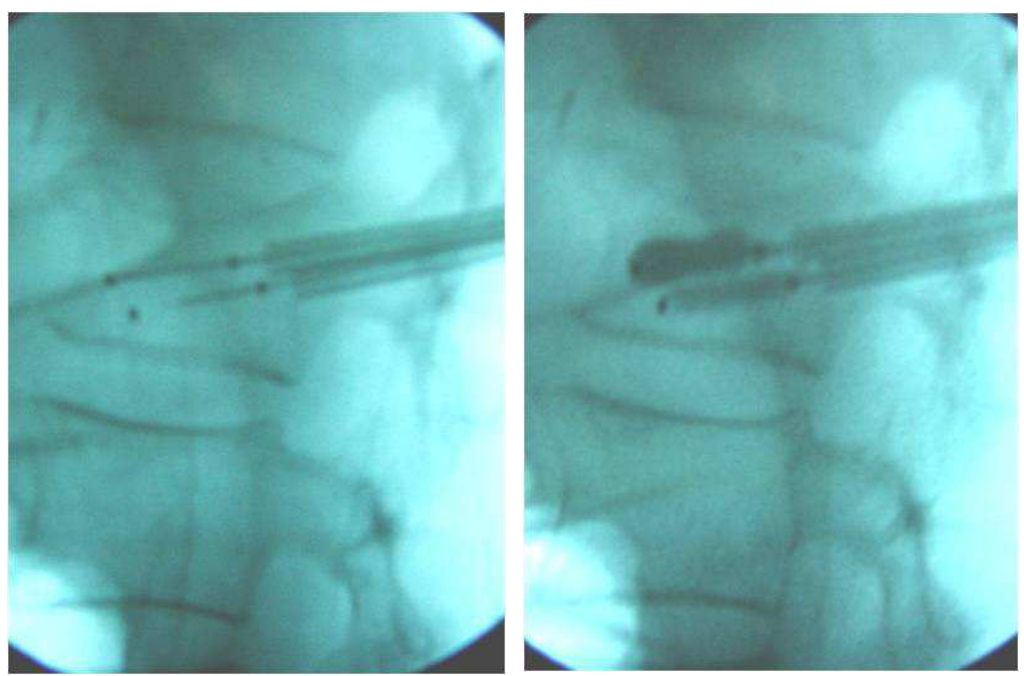

Fig. 4. Right: Insertion of Inflatable Balloon tamps. Left: Inflation of the Balloon tamps. 
The balloon is slowly deployed under fluoroscopic guidance until maximum fracture reduction is accomplished. (Figure 5)
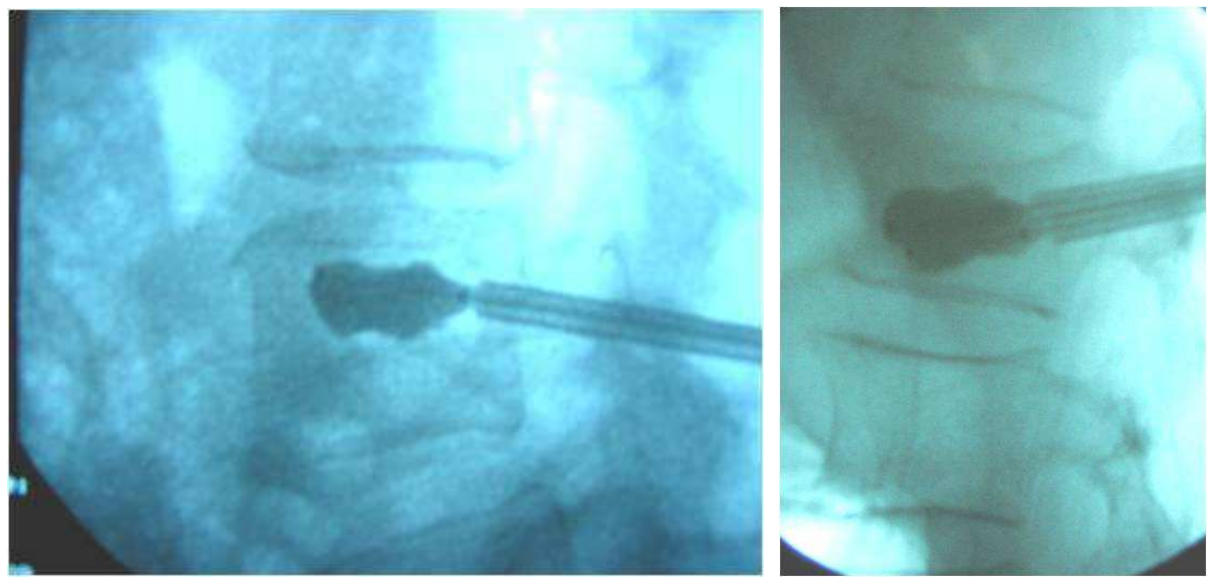

Fig. 5. Maximum fracture reduction under fluoroscopy.

The inflation is stopped when the balloons reaches the cortical wall; Or, when we have "balloon kissing" position in the bi-pedicular approach (Figure 6).

Balloon is deflated and subsequently removed when the cement is ready to be used.

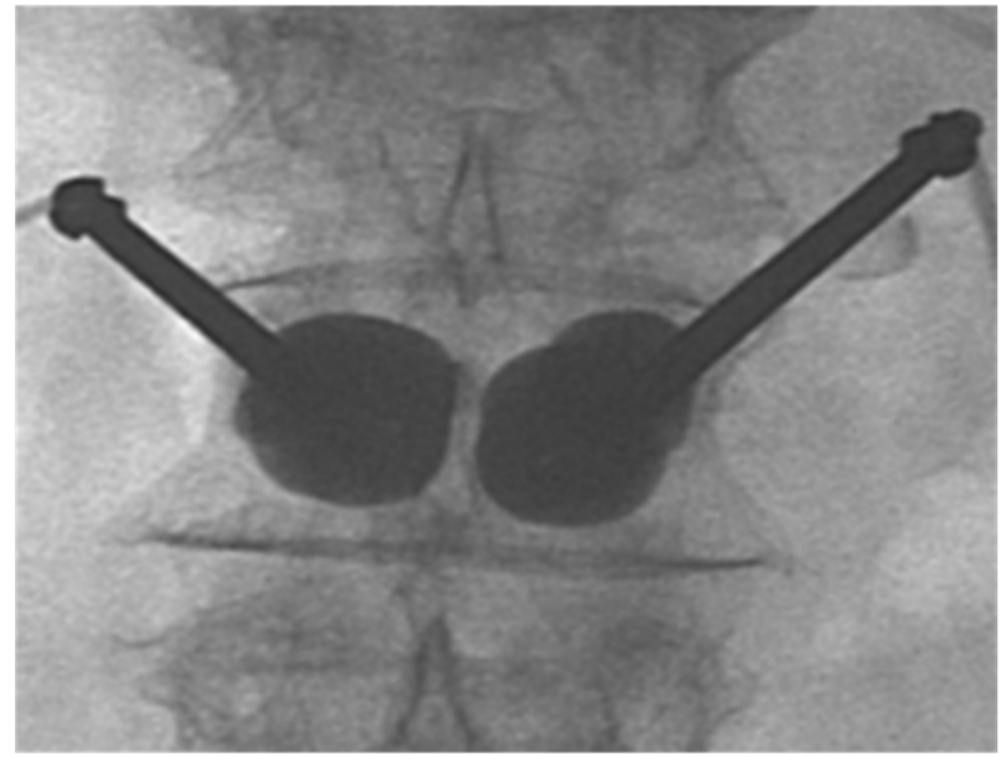

Fig. 6. Bipedicular Balloon tamps inflation, "Kissing Balloons”.

During inflation, an assistant prepares the cement to be injected.

The cement is polymethylmetacrelate that needs 5 minutes to reach its semi-solid constitution. It's loaded in 5 injection cannulas 
The cement is then injected into the vertebral body's created cavity meticulously under fluoroscopy.

From our observation, the cement fills the entire fracture tract first then it fills the created cavity.

Once packed and hardened, the cannula is removed.

The incision is closed by single cutaneous layer suture.
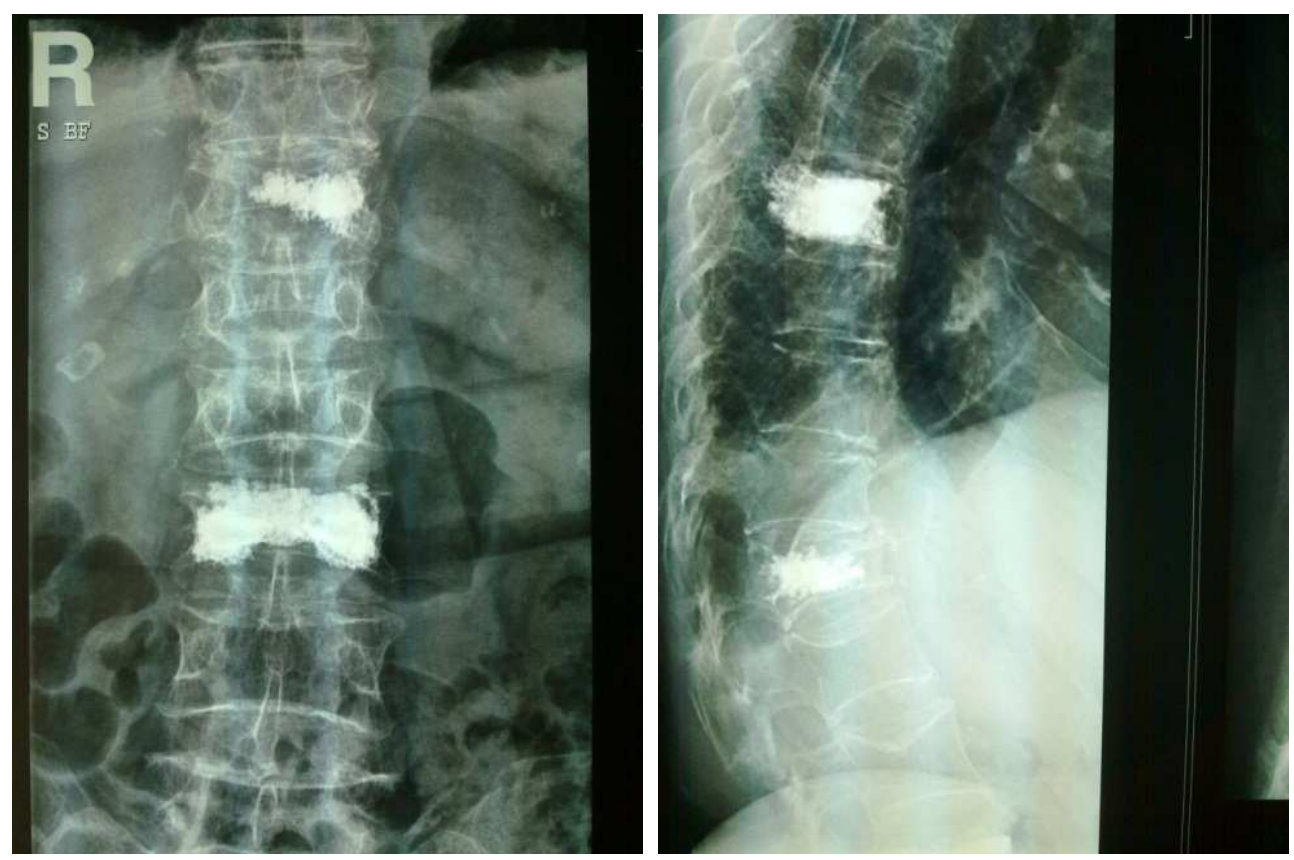

Fig. 7. Antero-posterior and lateral views of a case of 2 levels Kyphoplasty.

\subsection{Long term results}

As far as the inclusion criteria were respected and for osteoporotic fracture mainly, pain relief was achieved with 24 hours in more than $60 \%$ of cases.

The difference of pain relief and kyphotic deformity restoration are highly correlated to the time since the onset of the fracture. And though, patients presenting within 45 days showed optimal results. Whereas, patient presenting after 60 days necessitated moderate potency analgesics to achieve complete pain relief.

Long term follow up, after 3, 6 and 12 months shows an increase in number of cases relieved by the treatment to (70 - 82) \% of the population that doesn't necessitate any analgesic use. (6 - 8)\%, who already has radicular pain before the procedure, necessitated 3-6 months of Gabapentin treatment.

$1 \%$ necessitated another surgical procedure and, $9 \%$ achieved partial relieve of their pain. 

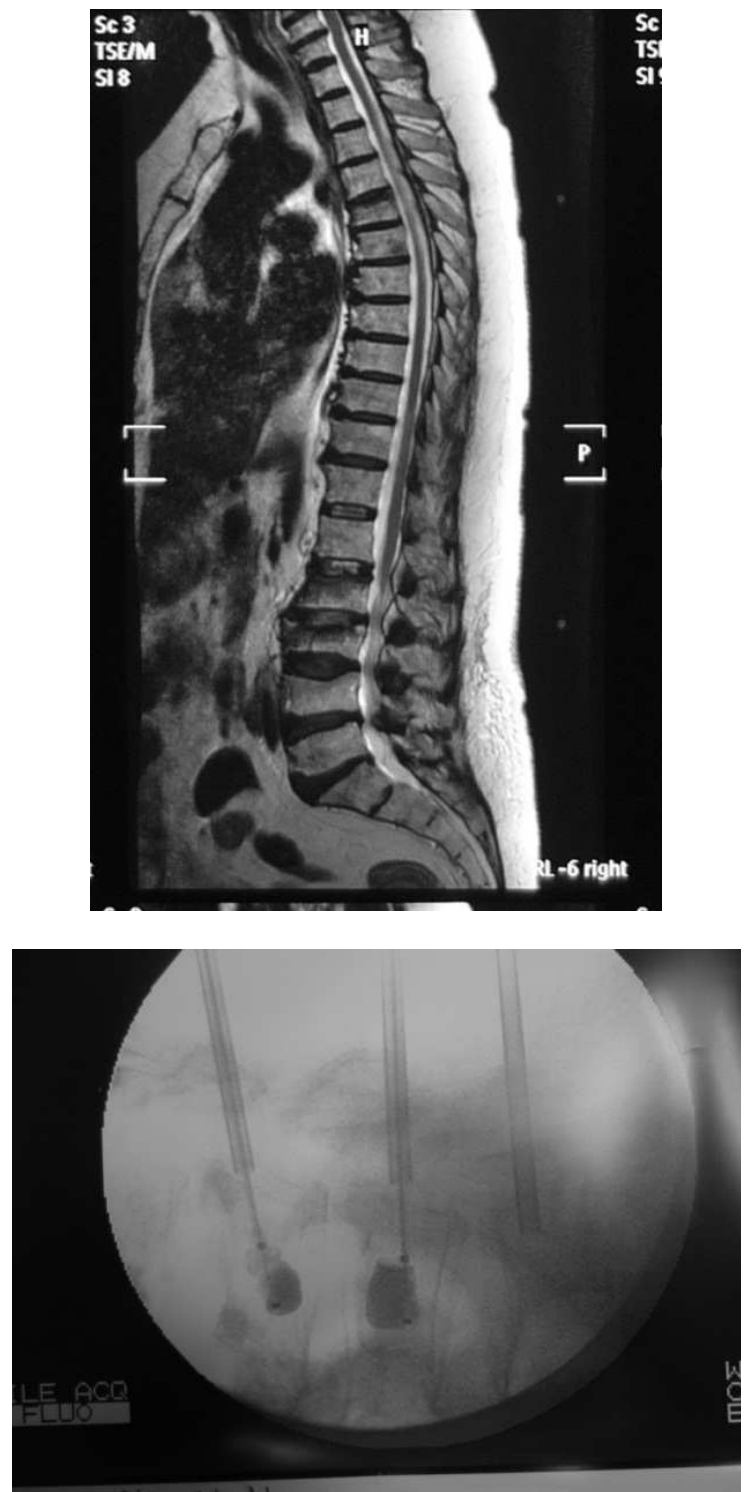

Fig. 8. Above: MRI of the lumbo-sacral spine showing L2-L3-L4 vertebral compression fractures. Below : Per-operative fluoroscopy after balloon inflation and reduction of vertebral height.

\subsection{Complications}

During balloon kyphoplasty, untoward effect is minimal (3 - 10) \%. Minor complications, as cardiopulmonary toxicity defined by transient bradycardia and desaturation, were the most common. 
Severe complications as cement pulmonary embolus (Perrin C et.al (1999)), extravasation to the epidural space or to the foraminae are rare (Moreland DB et.al (2001)). The risk of pulmonary embolism is $0.01-1 \%$. The rate of extrusions is $8.5 \%$. Nevertheless, most of these extrusions are clinically asymptomatic and the rate of serious problems remains low.

In the literature, the overall clinically significant rate of complication is described as $1 \%$.
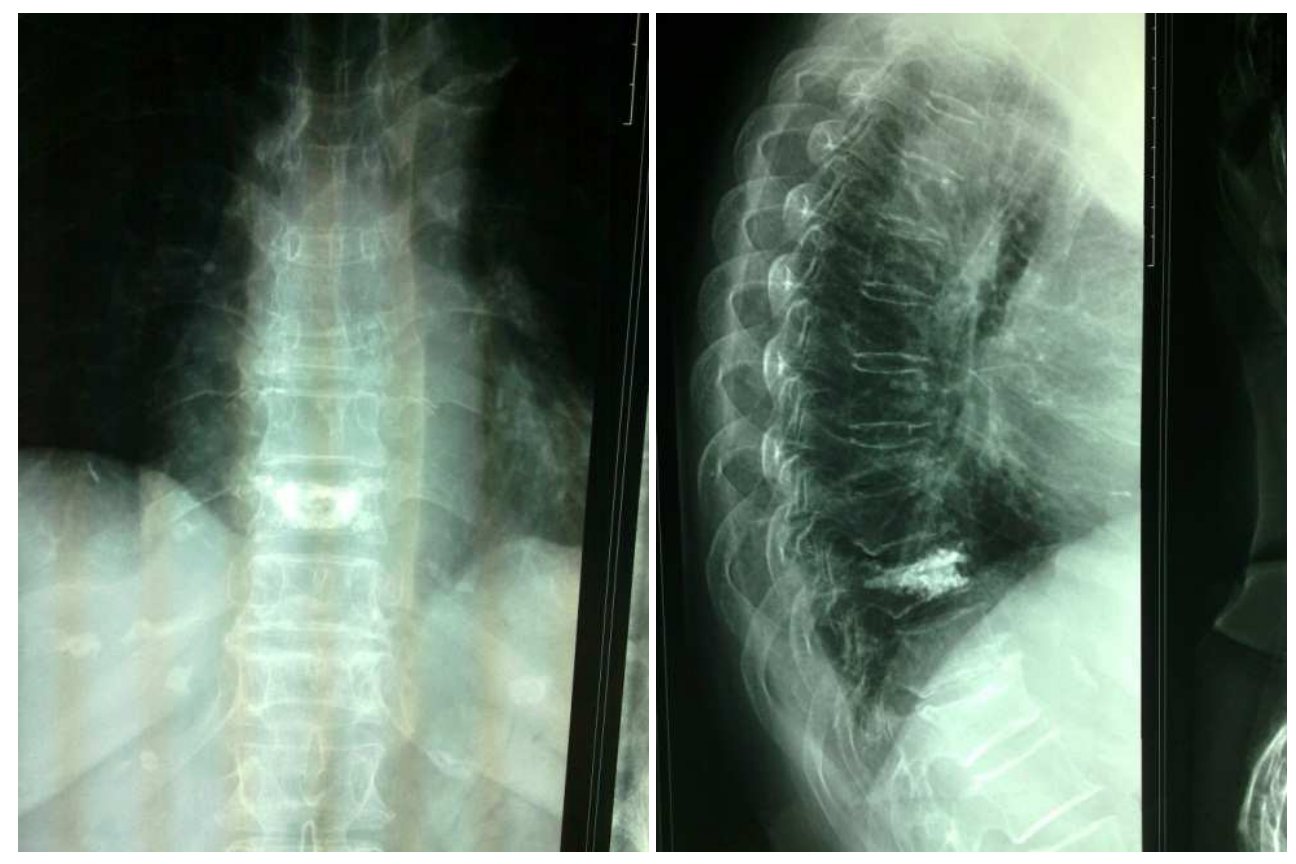

Fig. 9. A case of single level Kyphoplasty.

\subsubsection{How to avoid complications}

\subsubsection{Cement embolus}

Cement pulmonary embolus are due to hazardous extravasation of the cement to the venous system. The latter is avoided by ascertaining the position of the injector in the middle of the cavity created by the inflated balloon. Clinically, cement pulmonary embolism presents by desaturation with heart rate changes. Thus monitoring is mandatory during the procedure. The procedure should be stopped and management of expected cement pulmonary embolism should be started.

\subsubsection{Extravasation to the epidural space or foramina}

It's the most common complication (Figure 10). Two third of those patients will necessitate open surgical decompression. This complication can be avoided if cement is left to become thick for 5 minutes after injection and the removal of the cannula should be done slowly in rotating manner. 


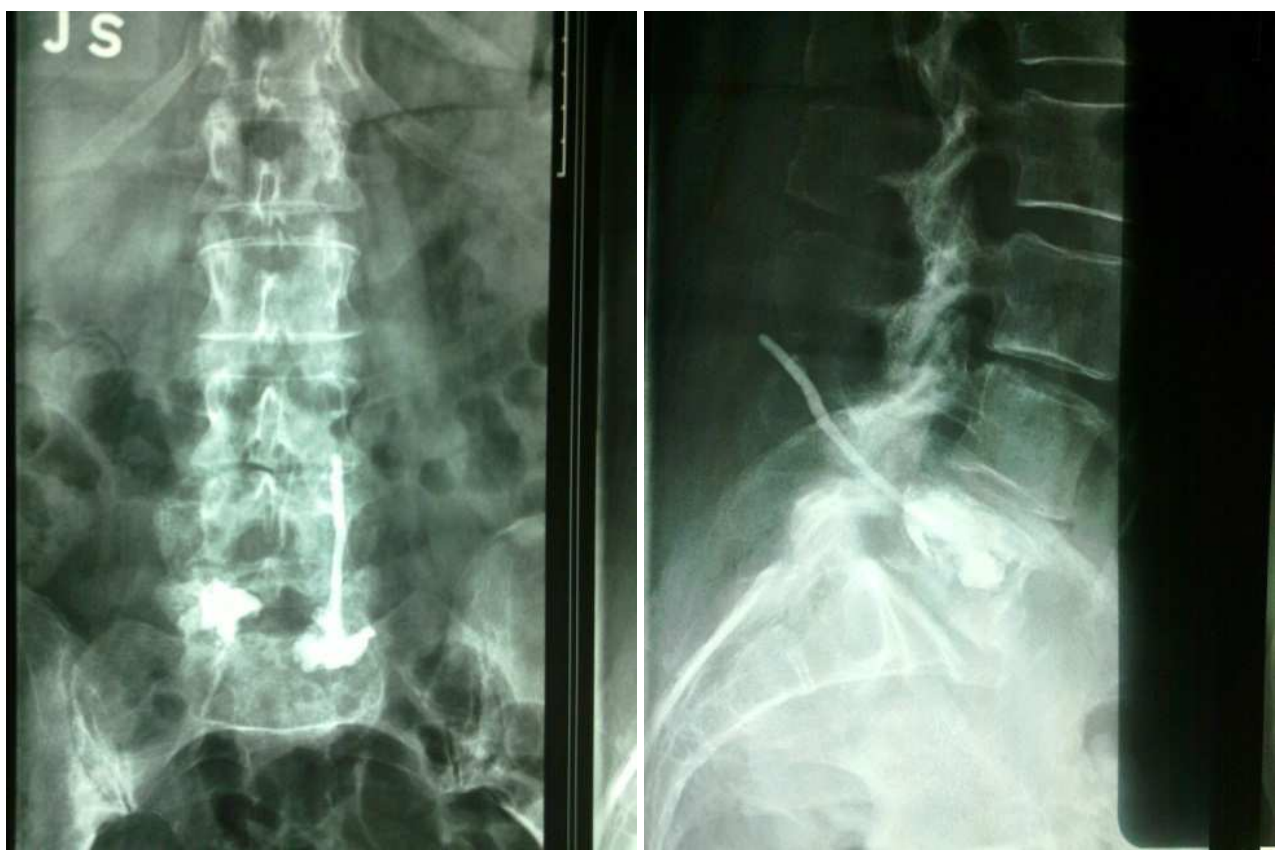

Fig. 10. Extravasation of the cement to the Epidural Space.

\section{Conclusion}

Despite being relatively a new technique, balloon kyphoplasty becomes popular. It showed, in all studies conducted, that it's an effective method for treating pain and kyphosis induced by osteoporotic vertebral fractures.

With the increase in indications and use of this technique, advancement in injection kits decreased the rate of complications.

In experienced, well trained hands in the field, balloon kyphoplasty is safe and efficient technique for several types of fractures.

\section{References}

Baroud G, Bohner M, Heini P, et al (2004) Injection biomechanics of bone cements used in vertebroplasty. Biomed Mater Eng 14: 487-504

Baroud G, Steffen T (2005) A new cannula to ease cement injection during vertebroplasty. Eur Spine J 14(5): 474-9

Becker, S. (2008). Balloon Kyphoplasty(Ogon, Micheal), Springer Wien New York, 978-3-21174220-4, Austria

Berlemann,U (2008). Results in kyphoplasty, risks and complications in: Balloon Kyphoplasty(Ogon, Micheal), Springer Wien New York, 978-3-211-74220-4, Austria

Bohner M, Gasser B, Baroud G, et al (2003) Theoretical and experimental model to describe the injection of a polymethylmethacrylate cement into a porous structure. Biomaterials 24: 2731-8 
Deramond, H Depriester C, Galibert P, Le Gars D (1998) . Percutaneous vertebroplasty with polymethylmethacrylate: technique, indications, and results. Radiol Clin North Am, 36, 533-546

Edidin AA, Ong KL, Lau E, Kurtz SM (2011). Mortality Risk for Operated and NonOperated Vertebral Fracture Patients in the Medicare Population. Journal of Bone and Mineral Research, 2011 Jul;26(7):1617-26

Garfin SR, Yuan HA, Reiley MA (2002). New technologies in spine: Kyphoplasty and vertebroplasty for treatment of painful osteoportic compression fracture. Spine, 26, $14,1511-1515$

Galibert P, Deramond H, Rosat P, Le Gars D (1987). Preliminary note on the treatment of vertebral angioma by percutaneous acrylic vertebroplasty. Neurochirurgie, 33,2,166-168

Johnell, O (1996). Advances in osteoporosis: better identification of risk factors can reduce morbidity and mortality. J Intern Med, 239, 299-304

Lieberman IH, Dudeney S, Reinhardt MK, Bell G (2001) Initial outcome and efficacy of kyphoplasty in the treatment of painful osteoporotic vertebral compression fractures. Spine 26(14): 1631-8

Moreland DB, Landi MK, Grand W (2001). Vertebroplasty, techniques to avoid complications. Spine J , 1: 66-71

Perrin C, Jullien V, Padovani B, Blaive B (1999). Percutaneous vertebroplasty complicated by pulmonary embolus of acrylic cement. Rev Mal Respir, 16: 215-217

Phillips, FM (2003). Minimally invasive treatements of osteoporotic vertebral compression fratures. Spine,28(15 suppl): S45-53

Taylor RS, Fritzell P, Taylor RJ (2007) Balloon kyphoplasty in the management of vertebral compression fractures: an updated systematic review and meta-analysis. Eur Spine J

Theodorou DJ, Theodorou SJ, Duncan TD, Garfin SR, Wong WH (2002). Percutaneous balloon kyphoplasty for the correction of spinal deformity in painful vertebral body compression fractures. Clin Imaging, 239:299-304

Vaccaro, A (2003). Spine surgery tricks of the trade (Thieme), Thieme New York Stuttgart, 158890-038-X, USA

Voggenreiter, G (2005). Balloon Kyphoplasty is Effective in Deformity Correction of Osteoporotic Vertebral Compression Fractures. Spine, 30, 24, 2806-2812

Wardlaw D, Cummings SR, Van Meirhaeghe J, Bastian L, Tillman JB, Ranstam J, Eastell R, Shabe P, Talmadge K, Boonen S (2009). Efficacy and safety of balloon kyphoplasty compared with non-surgical care for vertebral compression fracture (FREE): a randomized controlled trial. Lancet, 373, 1016 - 1024

Weißkopf, M. Weisskopf M, Ohnsorge JA, Niethard FU (2008). Intravertebral Pressure During Vertebroplasty and Balloon Kyphoplasty. Spine, 33, 2, 178-182 


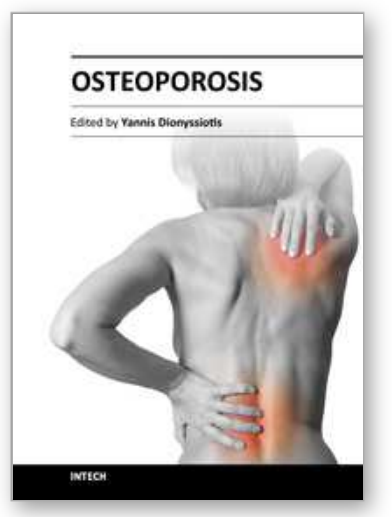

\author{
Osteoporosis \\ Edited by PhD. Yannis Dionyssiotis
}

ISBN 978-953-51-0026-3

Hard cover, 864 pages

Publisher InTech

Published online 24, February, 2012

Published in print edition February, 2012

Osteoporosis is a public health issue worldwide. During the last few years, progress has been made concerning the knowledge of the pathophysiological mechanism of the disease. Sophisticated technologies have added important information in bone mineral density measurements and, additionally, geometrical and mechanical properties of bone. New bone indices have been developed from biochemical and hormonal measurements in order to investigate bone metabolism. Although it is clear that drugs are an essential element of the therapy, beyond medication there are other interventions in the management of the disease. Prevention of osteoporosis starts in young ages and continues during aging in order to prevent fractures associated with impaired quality of life, physical decline, mortality, and high cost for the health system. A number of different specialties are holding the scientific knowledge in osteoporosis. For this reason, we have collected papers from scientific departments all over the world for this book. The book includes up-to-date information about basics of bones, epidemiological data, diagnosis and assessment of osteoporosis, secondary osteoporosis, pediatric issues, prevention and treatment strategies, and research papers from osteoporotic fields.

\title{
How to reference
}

In order to correctly reference this scholarly work, feel free to copy and paste the following:

Antoine Nachanakian, Antonios El Helou, Sami Salem and Moussa Alaywan (2012). Balloon Kyphoplasty for Osteoporosis: Technical Notes, Osteoporosis, PhD. Yannis Dionyssiotis (Ed.), ISBN: 978-953-51-0026-3, InTech, Available from: http://www.intechopen.com/books/osteoporosis/balloon-kyphoplasty-for-osteoporosistechnical-notes

\section{INTECH}

open science | open minds

\section{InTech Europe}

University Campus STeP Ri

Slavka Krautzeka 83/A

51000 Rijeka, Croatia

Phone: +385 (51) 770447

Fax: +385 (51) 686166

www.intechopen.com

\section{InTech China}

Unit 405, Office Block, Hotel Equatorial Shanghai

No.65, Yan An Road (West), Shanghai, 200040, China

中国上海市延安西路65号上海国际贵都大饭店办公楼405单元

Phone: $+86-21-62489820$

Fax: +86-21-62489821 
(C) 2012 The Author(s). Licensee IntechOpen. This is an open access article distributed under the terms of the Creative Commons Attribution 3.0 License, which permits unrestricted use, distribution, and reproduction in any medium, provided the original work is properly cited. 